\title{
Shaping the Good Pupil - Socialization, Normalization and Benevolent Governing in Two Swedish Schools
}

\author{
Åsa Bartholdsson \\ School of Education and Humanities, Dalarna University (Högskolan Dalarna)
}

\begin{abstract}
This is about the socialization of school children and how normality is learned and managed in one preschool class and one fifth grade class in the Swedish compulsory school. The Swedish school is, according to the National Curriculum based on democratic values and respect for the individual. In accordance with these values socialization of the pupil is, as the thesis argues, accomplished through 'benevolent government' by the teachers. Benevolent governing is exercised as the adapting of techniques that is not recognized as a normalizing conduct of conduct, but as an expression of good intention. It is a misrecognized exercise of power, uncomfortable to reveal itself as such. To enable benevolent governing, the pupil needs to learn how to be him or her 'self' according to norms about how the 'self' is to be expressed. The pupil also needs to learn how to balance multiple relations in school and the different aspects that constitutes the social person. Benevolent government is here used as a description of a certain kind of teacher practice, dependent on a certain kind of pupil. The pupil-subject that is constructed is a subordinated, self-inspecting, positive, empathic person who will approve of being governed by the teachers through the governing of themselves. The study is based on anthropological fieldwork during two years in these classes.
\end{abstract}

\section{Introduction}

This paper is about the socialization of schoolchildren and how normality and power relations are learned and managed in two Swedish school classes. The study is based on anthropological fieldwork through participant observation and interviews during two years in one preschool class and one fifth grade class in the Swedish compulsory school [1].

A central, analytical concept here is normality. It is usually in play as a invisible reference, a taken for granted, unproblematic state. My understanding of normality is also that it is not necessarily in need of a counterpart (deviance) to become visible. It has its own dynamic and we move through different notions of normality through the day and through a lifetime. Normality is also, following Ian Hacking [5] a concept that comments on both an is-aspect (what is most common) and an ought-to-be-aspect (how it should be). Normality is thus a two faced concept as it is understood as working both as description and prescription. In this study the normative ought-to-beaspect is of major importance.

Further elaborating on the normality concept, it is neither universal nor natural; it is contextual, situational and relational. It is a space of culturally approved actions. Normality is something that has to be learned, as in produced and reproduced and the process in which this learning takes placed is commonly named socialization.

Socialization is thus a normalizing process through which a person is introduced into certain ways of thinking, feeling and acting. It is a lifelong, interactive and inter-subjective process during which the individual learns how to manage relations in various social contexts. It is an on-going and mutual process whereby both children and adults continuously come into being as 'persons' [12]. Here socialization could be described as two parallel processes: one didactic and one auto-didactic.

The didactic socialisation project is a top-down practice where someone is having an intention to make someone else into something. Within the school context we can illustrate this as teachers leading pupils towards goals formulated in the national curriculum. These goals are about forming a certain kind of citizen that represents certain kind of values, as well as having certain kind of knowledge's and skills.

Another aspect of socialization emphasizes the auto-didactic qualities where children and adults figure out and learn for themselves and by themselves how to manage in the world and understand its multiple, fluxing normalities.

Even though the didactic intentions are to mould a future citizen, the actual practices during every day school life is, and here we enter into the world of "hidden curriculums" [7], even more a struggle to shape an institutional person - a pupil.

Here we need to consider the nature of the person. My analytical understanding of what a person is, differ from the well established emic 
notion which regards the individual as having an essential, authentic, true self. The realization of this self were the objective in many different situations during fieldwork. In a teachers manual for a program used in the fifth grade to work with social relations, cooperation, self evaluation and self-confidence. the author states [13]:

Certainly our children need knowledge, but not on expense of their self-confidence! It is of course the self-confidence that constitutes the best ground for acquiring knowledge. So let us begin with the basis as we help our children to become whole beings.

In this teacher's manual, school as an academic projects is subordinated in relation to the objective to make "our children into whole beings". Accirding to the text, the pupils need help to learn who they are, to find "a clear identity", "a safety base" and "a genuine self-confidence". The author is using a definition of identity as" [...] the ability to stay the same in the middle of changes". A person with a stable identity is described by the author as one that performs in the same way vis-à-vis everyone, treats everyone with the same respect, and see changes as interesting challenges. "It is such adult that we need to bring up for the challenges of the future"[13].

The person implied in the teachers manual is, from my reading, a person striped of various social and emotional relations. There is one way of being a person and, to add to this, this is a person always on his or hers toes to take on the challenge of change. This is the shapeable and at the same time static and predetermined person, that ideally resides in the classroom. I repeatedly heard teachers urge pupils to become who "they really are" or to be or become 'yourself'. I will return to this later.

In contrast to the emic notion about the person described above, the pupil is, within my analytical framework, to be understood as one of many aspects of a person's whole make up. Following the anthropologist Marilyn Strathern [10], I refer to the person as a 'social microcosm' whose contextual, situational and relational nature is understood as a 'dividual'. There is no self untouched by the social context. 'Pupilness' is thus activated and socialized in a particular setting, the school, in a particular set of relations, as a particular kind of normality.

From this perspective becoming a pupil is a question, is not about being "the same" regardless of context. To be a 'pupil' is to figure out how to manage this certain kind of normality and to be intertwined in multiple relations and in various contexts imbedded in everyday school life.

\section{The dilemmas of democracy}

In order to understand how this pupil socialization works within the school context we need to learn a bit more about the actual framework within which teachers and pupils are coming together in everyday school relations.

The Swedish school system rests strongly on liberal democratic values. To be a pupil is, as a didactic socialization project, to be subject to socialization into a certain kind of citizen - a democratic citizen. In the Curriculum for the compulsory school system, the preschool class and the leisure-time centre [11] the opening paragraph states:

Democracy forms the basis of the national school system. The Education Act (1985:1100) stipulates that all school activity should be carried out in accordance with fundamental democratic values and each and everyone working in the school should encourage respect for the intrinsic value of each person as well as for the environment we all share. The school has the important task of imparting, instilling and forming in pupils those fundamental values on which our society is based [11].

Even though compulsory school is just that compulsory - and in that respect forced upon children (and their parents), a somewhat romantic notion about children's presumed willingness to take responsibility for their own learning is expressed as a point of departure in the National Curriculum [11]. This is, however, challenged in a number of everyday relations and situations. Here we encounter the political dilemma occurring in a democratic society: How is the control of the citizen's virtues and morals to be executed when violence and force are incompatible with societal values such as respect for the individual and democratic principles?

To manage this dilemma the teachers in the study, as I will show here, turn to what $\mathrm{I}$, in a Foucauldian spirit calls 'benevolent governing'. Benevolence is exercised through care, therapeutic practices and democratic principles. It is now time to look closer to these practices as benevolent techniques.

\section{Benevolent techniques - audit and therapeutic practices}

'Benevolent government' is practiced by teachers and could be legitimized as an expression of compassion and concern for their pupils. It could be described as an expression of good intentions, wanting the best for the children. Beyond good intentions, benevolent governing could, however, also be understood as a way to exercise power - the 
conduct of others conduct $[3,8]$ - in a way not recognised as such. Even though the goal is to create classroom order and producing positive pupils, the benevolence is making it difficult to see beyond its good intentions. Thus, 'benevolent techniques' are applied to guide pupils towards achieving clearly formulated goals as well as to establish classroom order.

The tool-kit of benevolent governing comprises therapeutic and audit practices. The understanding of the use of therapeutic and audit techniques needs to be put in a wider context.

The focus on the well-being and emotional life of the pupils is to be understood as working within what is referred to by the Sociologist Frank Furedi as a 'therapy culture' [4] or a culture of emotionalism where people learn to understand themselves and their problems in terms of emotional issues. This is a context where a therapeutic ethos is cultivated within professional groups such as teachers. Focusing on the emotional life of the pupil person thus becomes part of professionalism. Emotions becomes a way of explaining the individuals shortcomings and problems as manifestations emanating from the inner psychological state of the person, rather than turning to structural explanations. It is through emotion work that these problems are addressed.

Here therapeutic culture meets up whit audit culture [9] as the use of evaluation and formulating goals becomes means to govern pupils. When audit technologies travelled from the arena of market economy into new sectors, they have been recharged with new meanings and generated new practices. In schools, audit (evaluations and inspections) have become parts of everyday school life on different levels. Here we can see a psychologization of audit practices, applied as tools for self-realization and self-evaluation. A focus on the person and the making of a special kind of citizen/institutional person, a pupil, is about setting as a goal to perform as a positive sanctioned subject, available to evaluation on a regular basis. One of the main goals for the individual to strive for is being reflexive, in order to act as a project of personal improvement (of becoming a better person), expressing the right kind of feelings in a positively sanctioned manner. Audit practices are well appt to support this.

Audit becomes a political technology of the self: a means through which individuals actively and freely regulate their own conduct and thereby contribute to the government's model of social order [9].

Audit appears as a seemingly neutral practice, a mild way to reorganize the pupil-person by having $\mathrm{him} / \mathrm{her}$ formulating personalized general goals and evaluate the development towards becoming a desired self-regulating institutional being. Pupils thus ideally govern themselves and achieve normality through emotional work, therapeutic practices and evaluation. Through therapeutic and audit practices the pupil becomes exposed as 'seeable'. This is ways of governing that serves to seek justification for authority in a democracy, as an answer to the crisis in authority [8]. So how is this benevolent governing rationalized by the governing agents - the teachers?

\section{School as 'reality' - as a discursive context}

'Welcome to reality', the principal of one of the schools of the study, greeted me one morning after I had involuntarily been involved with two children having a quarrel. This notion of reality is important in order to understand how socialization practices are shaped and how a benevolent governing is rationalized.

The notion of 'reality" is a kind of discursively constructed reference in relation to which children and teachers professionalism is partly understood. So what kind of reality are we talking about here? One important step towards understanding this is through examination of the knowledge or rather the discourses that blend and construct the school as "reality". Here, I argue that school, in addition to being governed by educational policy, is a discursive space where teachers' notions about society at large, about school itself, about parents and children 'today' are transmitted and understood in relation to dominant discourses.

We thus are introduced to the discourse about schools 'today' connected to emic notions about society at large and about school as a mirror of that society. Teachers in my field described Swedish society, even civilisation at large as falling apart; they described children "today" as individualistic and daring. To this we can add frequently occurring and alarming reports in the media about increasing 'mental ill-health' among Swedish children. Parents were considered too weak to frame their children's lives with authority; they were described as 'afraid of growing up' and lacked time for their children. School had, according to the teachers in my study, increasingly become an arena where 'upbringing' competes with academic education. This dominant discourse of misery shapes ideas about teacher professionalism and which aspects of socialization should be addressed in everyday school life.

The discourse of 'seeing' describes a way to deal professionally with children in this 'reality'. Within this discursive space 'seeing' as a teacher becomes a key competence grounded in a therapeutic ethos. The discourse of 'seeing' is thus, following those about children, parents and school today, one more professional discourse occurring as a consequence of what the other discourses claims to be reality. As a 
socialization practice in the shadows of the discourse of misery, teachers can focus on the emotional, personal aspects of children's socialization. Here programs for working with social and emotional training, comprising therapeutic and audit practises, provides teachers with arenas for 'seeing' and for pupils to be 'seen'.

\section{Constructing the good pupil}

Now we turn to the goals of these benevolent governing and what constitute the desirable pupil. We are now approaching the everyday life in school where children adapt to the rules and norms of being a pupil.

During fieldwork within the preschool class and the fifth grade, I could identify a number of qualities that constitutes the desired pupil-person. One of the most apparent quality was to be positive. To be positive appeared as a highly praised quality in children. Positive children are one of the best prerequisites for benevolent governing. Positive children are pleased and content with the order of things and they do not resist or question teacher authority. They don't need to be authored as they self-regulate. Strongly outspoken expectations for the children to be "positive", "alert" or "cheerful" were regularly observed in every day interactions. Pupils behaving like this were considered "Nice to deal with." as opposed to pupils considered as 'negative' or 'sullen'.

The be reflexive is another quality that was encouraged in a number of situations were different kinds of auditing and evaluation practises occurred. For example during progress review sessions held every semester with each student and his or her parent/s, judgments about the child's attitude were made and the child were encouraged to look at him/herself and work on improving his or herself both when it came to skills in mathematics, doing home works or behaving in the classroom. Almost every student appeared to have at least one minor behavioural problem such as talking too much, too loud, too little, at bad timings, bother to much over others, not remaining at his or her chair, complaining too much or having a tiresome, negative attitude. This way a goal could be formulated in order to improve the person, and to be evaluated in the next progress review session. The discussion aims at having the child identifying problems, agreeing to work to correct them. To seal this, a contract is written between pupil, parents and teacher - an act establishing consensus about the child being in need of approving his/her personality.

To be reflexive is a quality that forgives almost any wrongdoing. It is an act that would, in the end, produce positive, empathic and socially competent children. So, it is, besides being positive, important to be self-critical as a child. The teacher might stand as a role model in this by admitting her own minor shortcomings, but the focus is on the child. And the reflexivity expectation leans heavier on the child than on the teacher.

This is the case in one progress review session in the fifth grade where I listened to 11 year old Annie taking on all responsibility for her bad relation to the teacher. This was a surprising turn since I have repeatedly, during my stay in the fifth grade, listened to her complaints about how unjust she is treated by the teacher. But in this discussion she was talking about herself as insecure and, therefore, often being moody. The teacher was responding to this in a positive and confirmative way. She told Annie that people who know and who can admit they are doing something wrong have a good potential to change and people that do not see their own deficiencies can never improve themselves. Annie is here successfully mastering a discourse where being reflexive, self-critical and willing to improve herself are considered as a desired goals. Through this she is taking full responsibility for her bad relation to the teacher, also avoiding a potential conflict. To take responsibility, as Annie does, is yet another quality to obtain as a pupil.

Another important aspect of being a reflexive and evaluative pupil-person is the mastery of the proper expression of feelings. Emphasizing this as a matter of expressing rather than feeling, I follow Beatty [2] who argues that what might appear a socialization routine or a matter of training how to feel or modify feelings, could be interpreted as learning 'a language skill or social grace'. In order to become and be yourself, the pupils subject themselves to audit technologies, performing within an emotional discourse. At the progress review session Annie is skilfully bringing in (popular) psychological models of explanation as she starts to talk about herself as being insecure and therefore being moody.

Evaluation of oneself and the goals one sets for oneself are at the centre of attention here. As a pupil you have to make yourself visible to others through self-scrutiny and evaluation in order to acknowledge teachers' authority and to make benevolent government possible. To work with emotions is one way to conduct acceptable conduct through benevolent governing. Through the mastery of an emotional discourse, the pupils enable teachers to 'see'. By making the self visible as positive, reflexive and so on, the pupils at the same time, through an act of adapting to expectations and being unproblematic, make themselves invisible.

Audit practices were used in order to achieve reflexivity with the children. In the fifth grade they were sporadically writing in a personal "week book". In order to read their writing we need to consider the circumstances they were written under. This was something that the teacher had initiated and she was the audience to whom the writings were directed. For 
a period they should write about something good and something bad that happened during the past week. In the pupils texts, good things were often about playing with friends, being with the family or having a favourite school task. Bad things were often injuries, sickness, too much noise in the classroom and fights. At the time when I came in to the class, the writing should be a bit differently executed. Now they were supposed to write expectations for the week ahead and evaluate the past week. For the first two months these expectations were supposed to be relevant for time in school. Before the first leave in the spring term they were instructed to write about expectations about both school and their free time.

The writings in the books turned out to be focused on displaying the desired school-self. In the expectation/evaluation writings one thing stands out as maybe more important than many other things. This was about being positive or nice, being good to classmates and teachers followed by reflexive writings about whether you succeeded or you failed.

The self-regulating function of the week book becomes visible when Nina, the teacher, reveals to me that she does not read the week books. This is, she tells me, more a question of getting the children to be reflexive about their ways of behaving and attitudes towards schoolwork. The week book writings can thus be read as a way of staging themselves as having the right attitude, the positive spirit towards learning and towards people. Expectations have the character of "promises" and since the students do not know that the teacher does not read in their books, their writings are still in some way constraining. The books become a way of controlling children by their own doings. Here audit works with the logic of the panopticon in the foucauldian sense [3], self-regulating your behaviour, as if being watched, without actually being watched.

\section{The self-confident pupil}

An allied in the land of benevolent governing is, as has been touched upon earlier, the self-confident pupil. I will now turn to the actual execution of the exercise, mentioned before when exemplifying ideas about the "true" self, an exercise aiming at strengthening the pupils self-confidence [13].

Rosita divides the class in two group of girls and one group of boys. She takes out one group at a time while the rest of the class stays with their class teacher Nina for a lesson. Before the exercise, she presents the concept self-confidence and the differences between self-confidence and self-esteem according to the book's definitions and teacher's instructions. She brings this up for discussion with each group before they begin the exercise and explains, with some variations in the set-up, that self-confidence comes to be developed when you are very young, when you become confirmed by your parents. To become "confirmed", she explains, means that someone "sees" you. Then, you know that you are okay. Good self-confidence means that you can take criticism. To react negatively on criticism can therefore, Rosita says, be an expression of poor self-esteem. Poor self-esteem can also result in that you make yourself invisible in the group, or, on the other end of the scale, takes too much attention and becomes sturdy, offensive and tough " though you actually are very small". Rosita also tells them that you can" enlarge things" and that this is done in order to hide a poor self-confidence.

In the introduction to the exercise Rosita also stresses, that there is a difference between egoism and self-confidence. Egoism means that you want to be in the middle of attention; selfconfidence means that you believe in your own ability.

In the teacher's instructions it is urged that the teacher should point out how "extraordinarily important self-confidence is in order to succeed and to become whatever you have ability to be in life". When Rosita has gone through these fundamental explanations each pupil is given a form, "Form for reflections about myself", to fill out individually. The questions are about "my view of myself" and "views that I believe that others have [about myself]" regarding "my talent"; " my looks"; "my future dreams"; " my physical health"; "my role as a girl"; " my role as a boy", " my role as a son"; " my role as a daughter"; " my special aptitude"; "my ability to completed tasks"; "what my friends specially likes about me."

Several pupils expressed that it is a difficult task to fill out the form. Rosita gets questions as "what does this mean?" or, when it comes to responding to the question about how others consider you," how can I know that?"

As the exercise is taking place Rosita clarifies that being pleased with your self is something good. That it is not boasting. Still the pupils makes modest, brief responses as, "good", ", normal", "sufficiently" or" do not know ". In response to the question of dreams for the future the write " artist", " football pro", " lawyer" and "doctor".

The next step is to go through each form and discuss the answers in the group.

Rosita's introduction to this exercise established a common knowledge about self-confidence, how it is cultivated and how it is expressed. A good self confidence is the property of a modest personality, a person that would neither demand too much attention 
nor hiding away in invisibility. It is a pupil that can stand being corrected and criticized without rejecting it or resisting it.

Being self-confident is a sibling to the quality of 'being yourself". To be yourself was something that the pupils repeatedly were encouraged to be, or become. Pupils that were, for example, critical, sullen, tough or quiet should work on this appearance. For John, a boy in the fifth grade, this was a frequently occurring goal formulated at his progress review session. John was a academically skilled pupil, a football player that had a high status with his peers. Since he found school a bit boring he often questioned the purpose of different school tasks and challenged Nina's authority. The goals he should work towards were not academic goals, but personal ones. He was to work on being 'nice to everybody'. to' be yourself' or 'think about how you should be' or 'be the nice guy you really are'. Here the true self comes to life through instruction and is not attuned with questioning or being bored with school.

The self-confident pupil, the pupil being 'yourself', appears as an ideal institutional person, being at the center of normality. It is also a person that authorizes access to very personal reflections about ones place in the world in other people's eyes. It is a person that authorizes benevolent governing.

\section{Provoking benevolence}

The ideal positive, self-regulating child is, however, not always the child that meets the teacher. Obstruction and 'sullenness' is calling for a more explicit conduct of conduct in order to mark out the approved space for action, to normalize. As an example of this I will now introduce Amanda, an 11 year old girl in the fifth grade. She is having a difficult relation to the teacher, Nina, who considers Amanda to be sullen and tough (and thus needs to work on her attitude and here self-confidence). Below we meet Amanda in a situation with her class teacher and her woodwork group.

The teacher in woodwork has sent a note to Nina, the class teacher about "some of the children" (no names mentioned) having a negative attitude towards his subject. Nina's reaction is very strong and she takes the whole woodwork group out in the corridor to straighten this out with them. Amanda and Maude were pointed out by some of the other children in the group to be negative and sullen. From this moment Nina is focusing on Amanda and the discussion is carried out in front of the whole woodwork group. Amanda's voice is trembling and her eyes are fixed at Nina as she speaks.

Amanda is protesting against her being blamed for the whole problem. She thinks woodwork is boring and difficult and she is telling Nina that she does not get appropriate help from the woodwork teacher. If he had been given her help she would not have been sullen. Nina says that Amanda has to take responsibility for her own actions and not discuss what the other teacher should have done. She also tells Amanda that having a negative attitude only "hits back" on herself (that is: will have a bad effect on her). The discussion goes into a loop. Finally Amanda states that she is 'born with the wrong attitude. You can't do anything about it. This is how I am!' Tears are burning in her eyes. Nina tells her to behave herself in the future and everybody is ordered back into the classroom. Amanda is staying behind, sitting in a corner. I stay behind too to see how she is. She tells me she wants to be alone, so I leave her. On my way back to the class I pass by Nina and the other girl, Maude, in the corridor. Nina is telling her that she should not be like Amanda. Teacher says that she knows Maude as a nice and positive girl and she should be aware to get involved in this kind of situations.

During the next lesson in woodwork Amanda wants to tell me something in confidence. She tells me that the message from the woodwork teacher would not had been such a big deal if it was not because Nina were so worried about their reputation. I ask her in what way and whose reputation? Amanda says that Nina is worried about her own reputation. That someone should think she can't manage her own class. The girls that have their seats next to Amanda agree. They say I must not tell Nina.

Here we can witness how a bad attitude actually 'hits back' on Amanda, as her attitude and her person is exposed in front of her peers in a normalizing act. There is, however, a limit for how much Amanda is accepting the modeling of her attitude, and the responsibility she has to take for teacher's actions and their internal relations. Referring to the self as something essential (being born with a bad attitude), she is turning the notion about the true self, the constant self, into her favor. To challenge the notion of the essential, authentic self, that the teacher in other situations refers to as a desirable goal to reach, becomes a way of resisting and escaping the pressure put on her.

\section{Conclusion}

Benevolent government is here used as a description of a certain kind of teacher practice, aiming at producing a certain kind of institutional person - the pupil. Benevolent governing is understood as a way for teachers, motivated in part by a therapeutic ethos, to avoid, and handle dilemmas raised when democratic principles, respect for the individual and a notion that upbringing has come to be a featured part of teacher professionalism. It is a way of exercising power in 
order to avoid encounters with pupils who will not adjust to the school system, refuse to conform according to school norms or simply question teacher authority. The pupil-subject that is constructed is a subordinated, self-inspecting, positive, empathic person who will approve of being governed by the teachers through the governing of themselves. The teachers good intentions appears to shadow the exercise of power, the conduct of conduct taking place. This hidden form of normalization is difficult to defend against as it is not acknowledge as an exercise of power, neither by teachers, nor pupils..

Through instruction and experiences, such as the ones described above, children learn the boundaries of normality and acceptable ways to act. This is an intricate balancing of different aspects of the person which are activated in an array of simultaneously upheld relations. In this social microcosm, the pupil must handle multiple expectations on who s/he is and how s/he should be. The pupil has to manage being a child in relation to adults and being a peer in relation to other pupils

\section{References}

[1] Bartholdsson, Å, Med facit i hand. Normalitet, elevskap och vänlig maktutövning $i$ två svenska skolor. (Diss. in Swedish) Department of Social Anthropology, Stockholm University, 2007.

[2] Beatty, A. "Emotions in the field: What are we talking about?" Journal of Royal Anthropological Institute, vol. 11:s.17-37, 2005.

[3] Foucault, M. Discipline and Punish: The Birth of the Prison, New York: Vintage Books, 1979

[4] Furedi, F. Therapeutic Culture: Cultivating Vulnerability in an Uncertain Age. London: Routledge, 2003

[5] Hacking, I. The taming of chance. Cambridge: Cambridge university press, 1990.

[6] Inda, J. X. red Anthropologies of Modernity. Foucault, Governmentality, and Life Politics. Cornwall: Blackwell Publishing, 2005

[7] Jacksson, P. Life in Classrooms. New York: Teacher Collage Press, 1967

[8] Rose, N. Inventing Our Selves. Psychology, Power, and Personhood. Cambridge: Cambridge University Press, 1998.

[9] Shore, C. \& Wright, S. "Coercive accountability. The rise of audit culture in higher education". Audit Cultures. Anthropological studies in accountability, ethics and the academy. M. Strathern (red). London: Routledge, 2000

[10] Strathern, M, The gender of the gift: problems with women and problems with society in Melanesia. Berkley: University of California Press, 1988.
[11]The Swedish national agency for education. Curriculum for the compulsory school system, the preschool class and the leisure-time centre, , 1998

[12] Toren, C, Mind, Materiality and History. Explorations in Fijian Ethnography. New York: Routledge, 1999.

[13] Wahlström, G, Gruppen som grogrund: En arbetsmetod som utvecklar. Stockholm: Liber, 1993 